\title{
ESTUDO DE GEOTERMIA RASA NA CIDADE DE HUMAITÁ-AM
}

\author{
Elizabeth Tavares Pimentel ${ }^{1}$, Rutenio Luiz Castro de Araujo², \\ lerecê Barbosa Monteiro ${ }^{3}$ e Roberto Matias da Silva ${ }^{4}$ \\ Recebido em 31 agosto, 2009 / Aceito em 20 agosto, 2010 \\ Received on August 31, 2009 / Accepted on August 20, 2010
}

\begin{abstract}
From October 2007 to September 2008 a geothermal monitoring experiment was conducted at depths of $0.02 \mathrm{~m}, 0.5 \mathrm{~m}$ and $1.0 \mathrm{~m}$ to quantify the variations of temperature, thermal conductivity and the shallow geothermal heat flow at places with and without vegetation cover in the Humaitá city, Amazonas. The influence of the vegetation cover on the shallow geothermal system was observed in the sites studied. There were variations of monthly average values of temperature between the places with and without vegetation cover. During the "dry" period, this variation was up to $6.01^{\circ} \mathrm{C}$ at the depth of $0.02 \mathrm{~m}$, and $2.84^{\circ} \mathrm{C}$ at the depth of $1.0 \mathrm{~m}$. During the "rainy" period, however, the variation was up to $2.94^{\circ} \mathrm{C}$, at the depth of $0.02 \mathrm{~m}$, and $2.51^{\circ} \mathrm{C}$ at the depth of $1.0 \mathrm{~m}$. The difference of the daily extreme values of temperature between sites with and without vegetation cover were $3.97^{\circ} \mathrm{C}$ during the "rainy" period and $9.63^{\circ} \mathrm{C}$ during the "dry" period, at the depth of $0.02 \mathrm{~m}$. It was noticed that at 06:00 PM the magnitude of the temperature remained high compared to other times on the day studied. The values of the thermal conductivity were $0.54 \mathrm{~W} / \mathrm{m}^{\circ} \mathrm{C}$ during the "dry" period, and $1.23 \mathrm{~W} / \mathrm{m}^{\circ} \mathrm{C}$ during the "rainy" period. The values of the shallow geothermal flows at depths of $0.5 \mathrm{~m}$ and $1.0 \mathrm{~m}$, were $2.51 \mathrm{~W} / \mathrm{m}^{2}$ and $0.64 \mathrm{~W} / \mathrm{m}^{2}$, respectively. These values are $10^{3}$ larger than the terrestrial heat flow in the region. The thermal variations at $0.5 \mathrm{~m}$ to $1.0 \mathrm{~m}$ depth are influenced by external sources that reach the surface and cannot be neglected. The thermal variations recorded in this work are important and fundamental to better understanding the shallow geothermal structure in the southern, part of Amazonas state, and they also contribute as input to models that allow the mitigation or elimination of the effects caused by anthropogenic actions.
\end{abstract}

Keywords: shallow geothermic, temperature, vegetation cover effect, thermal conductivity, shallow geothermal flow.

RESUMO. No período de outubro de 2007 a setembro de 2008 foi realizado monitoramento geotermal, às profundidades de 0,02 $\mathrm{m}, 0,5 \mathrm{~m}$ e 1,0 m, em locais com e sem cobertura vegetal, na cidade de Humaitá (AM), a fim de quantificar as variações de temperatura, condutividade térmica e fluxo geotermal raso local. Quantificou-se a influência da cobertura vegetal sobre o regime geotermal raso na região estudada. Houve variação dos valores médios mensais da temperatura nos locais cc e sc. No período "seco", esta variação foi de até $6,01^{\circ} \mathrm{C}$ à profundidade de $0,02 \mathrm{~m}$, e de $2,84^{\circ} \mathrm{C}$ à profundidade de $1,0 \mathrm{~m}$; já no período "chuvoso", a variação foi de até $2,94^{\circ} \mathrm{C}$ a $0,02 \mathrm{~m}$ de profundidade e de $2,51^{\circ} \mathrm{C}$ à profundidade de $1,0 \mathrm{~m}$. Na profundidade de $0,02 \mathrm{~m}$, a diferença entre $0 \mathrm{~s}$ valores diários máximos, nos locais cc e sc, foi de $3,97^{\circ} \mathrm{C}$ no período "chuvoso" e de $9,63^{\circ} \mathrm{C}$ no período "seco". Às $18 \mathrm{~h}$, as magnitudes da temperatura permaneceram elevadas em relação aos outros horários estudados. Os valores de condutividade térmica foram de $0,54 \mathrm{~W} / \mathrm{m}^{\circ} \mathrm{C}$ no período "seco" e de $1,23 \mathrm{~W} / \mathrm{m}^{\circ} \mathrm{C}$ no período "chuvoso". Os valores do fluxo geotermal raso, às profundidades de $0,5 \mathrm{~m}$ e $1,0 \mathrm{~m}$, variaram até $2,51 \mathrm{~W} / \mathrm{m}^{2}$ e $0,64 \mathrm{~W} / \mathrm{m}^{2}$, respectivamente. Tais valores são da ordem de $10^{3}$ acima do valor do fluxo térmico terrestre profundo na região. As variações termais a $0,5 \mathrm{~m}$ e a $1,0 \mathrm{~m}$ de profundidade são influenciadas por fontes externas que atingem a superfície e não podem ser negligenciadas. As variações térmicas registradas neste trabalho são importantes e fundamentais para 0 melhor conhecimento da estrutura geotermal rasa na cidade de Humaitá (AM), como também, contribuem para a elaboração de modelos que possibilitem mitigar ou eliminar os efeitos causados por ações antrópicas.

Palavras-chave: geotermia rasa, temperatura, cobertura vegetal, condutividade térmica, fluxo geotermal raso.

\footnotetext{
1Universidade Federal do Amazonas/IEAA, Rua Campo São Cristóvão, 182, apto. 208, Bairro Imperial de São Cristóvão, 20921-440 Rio de Janeiro, RJ, Brasil. Tel.: (92) 9132-2647; Fax : (21) 2589-7463 - E-mail: bethfisica@on.br

2Universidade Federal do Amazonas, Rua ON, 7, casa 3, Conjunto Morada do Sol, Aleixo, 69060-068 Manaus, AM, Brasil. Tel.: (92) 8148-9621

-E-mail: ruie@ufam.edu.br

3 Universidade do Estado do Amazonas, Av. Efigênio Sales, 530/502, Adrianópolis, 69070-500 Manaus, AM, Brasil. Tel.: (92) 8182-3870

-E-mail: ierecebarbosa@yahoo.com.br

${ }^{4}$ Fundação de Tecnologia do Estado do Acre (FUNTAC), Av. das Acácias, Lote 01, Zona A, Distrito Industrial, 69917-100 Rio Branco, AC, Brasil. Tel.: (68) 3229-1665

-E-mail: roberto.matias@uol.com.br
} 


\section{INTRODUÇÃo}

As atividades de desmatamento devido à exploração de madeira na região sul do Amazonas, como também, áreas de floresta natural sendo substituídas por áreas de pastagens e produção agrícola, fazem parte de uma realidade difícil de ser mudada e vem aumentando nos últimos anos. As consequências são as mais diversas possíveis, causando vários distúrbios ambientais, em níveis local, regional e global (Roy et al., 1971; Lean et al., 1996; Chu et al., 1999; Dickinson \& Kennedy, 1999; Kalnay \& Cai, 2003; Araujo et al., 2004; Souza et al., 2006; Oliveira et al., 2006, 2008). Sem dúvida, um dos principais distúrbios refere-se às ampliações significativas das magnitudes das variações das temperaturas em superfície e em subsuperfície nas regiões afetadas. Tais variações são analisadas através do estudo da geotermia rasa, que investiga o comportamento e efeitos termais nas camadas do solo e subsolo afetadas significativamente pelo fluxo de radiação solar incidente na superfície sólida da Terra (Araujo et al., 2004). A incidência direta da radiação solar sobre a superfície da Terra pode acarretar efeitos no clima, nas propriedades físicas do solo, na biodiversidade e nos processos de regeneração florestal.

A literatura clássica registra que as perturbações térmicas, provocadas pela incidência do fluxo de radiação solar na superfície terrestre, propagam-se em direção às camadas subsuperficiais sendo, no entanto, mensuravelmente atenuada com 0 incremento da profundidade (Carslaw \& Jaeger, 1959; Beck, 1965; Bowen, 1966; Astier, 1975). Tais autores ressaltam, inclusive, que a atenuação dessa perturbação térmica é tão intensa, que a variação termal diurna é eliminada a 1,0 m de profundidade, enquanto que a variação térmica sazonal atinge profundidades da ordem de 25,0 a 30,0 m. Essas pesquisas foram realizadas em áreas com características diferentes das zonas tropicais úmidas.

Resultados de trabalhos científicos na Amazônia, como os de Araujo et al. (1984), Araujo (1987), Serra et al. (1997), PaIha et al. (1998), Araujo (1999), Serra (2002), Araujo et al. (2004), Oliveira et al. (2006, 2008), registram perturbações geotérmicas, tanto diurnas quanto sazonais, em profundidades superiores em relação a outras regiões. Considera-se que tais diferenças registradas nessas profundidades são oriundas, principalmente, de variações locais, tais como tipo de proteção vegetal superficial, fluxo geotermal raso e parâmetros climáticos (precipitação pluviométrica, evaporação, umidade do ar, insolação e evapotranspiração). Esta pesquisa, realizada na cidade de Humaitá, na região sul do Estado do Amazonas, mostra variações termais às profundidades de $0,02 \mathrm{~m}, 0,5 \mathrm{~m}$ e 1,0 m, e que essas variações são significativas a 1,0 m de profundidade, portanto, ratifica os resultados destes últimos autores.

\section{PROCEDIMENTOS METODOLÓGICOS}

A cidade de Humaitá está situada ao sul do Estado do Amazonas, localiza-se à margem esquerda do rio Madeira, afluente da margem direita do Rio Amazonas; dista cerca de 200 km da cidade de Porto Velho (R0) e $675 \mathrm{~km}$ da cidade de Manaus (AM), pela Rodovia BR-319 (Embrapa, 1997). Nesta cidade foram perfurados dois furos de $1,0 \mathrm{~m}$ de profundidade, nos quais foram realizados programas de monitoramento geotermal, durante um ciclo de um ano, estando um destes furos em local com cobertura vegetal (cc), com coordenadas geográficas de $7^{\circ} 30^{\prime} 26,7^{\prime \prime} \mathrm{S}$ e $63^{\circ} 01^{\prime} 34,0^{\prime \prime} \mathrm{W}$ e 0 outro furo em local sem cobertura vegetal (sc), com coordenadas geográficas de $7^{\circ} 30^{\prime} 26,8^{\prime \prime} S$ e $63^{\circ} 01^{\prime} 35,0^{\prime \prime} \mathrm{W}$.

Neste município os solos sob vegetação de campo nativo e sob mata possuem atributos químicos semelhantes e mineralógicos idênticos (Martins et al., 2006). Nos locais estudados os solos apresentam estrutura inconsolidada maciça, possuindo textura médio-argilosa a essencialmente argilosa, vermelho alaranjado, com pequenas quantidades de material arenoso de granulometria muito fina, com pouca variação em seus teores ao longo dos furos. Também apresentam grande concentração de ferro, com coloração avermelhada intensa.

Nos dois furos foram instalados sensores de termistor. Os sensores foram fixados na extremidade de um fio condutor e enterrados às profundidades de $0,02 \mathrm{~m}, 0,5 \mathrm{~m} \mathrm{e} \mathrm{1,0} \mathrm{m}$. A outra extremidade do fio foi conduzida a uma sala localizada à aproximadamente $23 \mathrm{~m}$ distante dos furos, onde foram lidas as medidas de resistência elétrica com o emprego de um multímetro digital. A superfície foi considerada a 0,02 $\mathrm{m}$ de profundidade no solo.

Os termistores foram calibrados utilizando-se a equação de calibração teórica existente na literatura (Araujo et al., 2004; Hiodo et al., 2007), e os dados do fabricante, ou seja,

$$
R=R_{o} e^{\beta\left[\left(\frac{1}{T}\right)-\left(\frac{1}{T_{o}}\right)\right]}
$$

onde:

$T$ - temperatura absoluta do termistor

$R$ - resistência do termistor à temperatura absoluta $T$

$R_{o}$ - resistência do termistor à temperatura de referência $T_{o}$ $\left(R_{0}=5 \mathrm{k} \Omega\right)$

$T_{o}$ - temperatura do ambiente $\left(T_{0}=25^{\circ} \mathrm{C}=298 \mathrm{~K}\right)$

$\beta$ - parâmetro característico do termistor, dependente da sua composição ( $\beta=3988 \mathrm{~K})$. 
Para ratificar a calibração dos termistores feita pela equação teórica (1), foi realizado um experimento usando-se um banho térmico com temperatura regulável. Foi medida a resistência elétrica do termistor a diferentes temperaturas e comparou-se com os valores obtidos pela equação teórica (1). Os valores de temperatura do sensor, obtidos pelos dois métodos, diferiram entre si em cerca de $2 \%$. As variações da temperatura foram registradas com precisão de $\pm 0,01^{\circ} \mathrm{C}$.

Com os dados supra citados foi possível a elaboração de uma curva de calibração que permitiu a conversão dos valores medidos da resistência elétrica dos termistores em valores precisos de temperatura.

Através dos termistores instalados nos furos, via fiação até a sala de monitoramento, foram efetuadas medidas diárias dos valores da temperatura às profundidades de $0,02 \mathrm{~m}, 0,5 \mathrm{~m}$ e $1,0 \mathrm{~m}$, nos horários das $8 \mathrm{~h}, 13 \mathrm{~h}$ e $18 \mathrm{~h}$. Tal procedimento propiciou o monitoramento das variações diurnas e sazonais da temperatura por um período de doze meses, ou seja, de outubro de 2007 a setembro de 2008. Estes resultados permitiram, então, 0 conhecimento do estado atual da estrutura geotermal rasa e suas variações temporais até $1,0 \mathrm{~m}$ de profundidade.

As medidas de condutividade térmica foram realizadas através do método transiente de calor, utilizando-se 0 aparato tipo agulha. Este aparato é similar aos descritos por Von Herzen \& Maxwell (1959), Smith (1973), Carvalho (1981), Araujo (1999), Araujo et al. (2004) e Souza et al. (2006). 0 aparato tipo aguIha utilizado consiste em uma fonte de corrente contínua, uma fina agulha hipodérmica e um multímetro digital. No interior da agulha há um fio aquecedor e um termistor localizado em seu ponto médio. Para efetuar as medidas de condutividade térmica, a agulha foi inserida na amostra a ser analisada e após 0 sistema (agulha-amostra) atingir o equilíbrio térmico, foi ligada à fonte de corrente contínua. Isto provocou 0 aquecimento da sonda cuja temperatura, registrada pelo termistor, varia com 0 tempo segundo a relação (Carslaw \& Jaeger, 1959):

$$
T_{S}=\left(\frac{Q_{s}}{4 \pi \lambda}\right) \ln (t)+C
$$

onde:

$T_{S}$ - temperatura da sonda

$t$ - tempo medido a partir do início do aquecimento da agulha

$Q_{s}$-fluxo de calor, por unidade de comprimento, produzido dentro da agulha pelo fio aquecedor

$\lambda$ - condutividade térmica da amostra analisada

$C$ - constante
0 gráfico dos valores registrados de $T_{s}$ em função de $\ln (t)$ resulta em uma relação linear cuja inclinação é dada por:

$$
D=\frac{Q_{s}}{4 \pi \lambda}
$$

Assim sendo, desde que seja conhecido o valor de $Q_{s}$, a condutividade térmica da amostra analisada é determinada pela Equação (3). 0 aparato tipo agulha utilizado neste trabalho apresenta as seguintes características: $R=361 \Omega$ (resistência do fio aquecedor)

$L=6,3 \mathrm{~cm}$ (comprimento da agulha)

$V c c=15 \mathrm{~V}$ (diferença de potencial aplicada entre os terminais do fio aquecedor).

Para os parâmetros acima indicados no presente trabalho tem-se que:

$$
Q_{s}=9,89 W \cdot m^{-1}
$$

Foram realizadas medidas de condutividade térmica em amostras de solo coletadas nos meses de março e outubro. Na região Amazônica, o mês de março é representativo do período de maior índice de precipitação pluviométrica, enquanto que o mês de outubro é representativo do período de menor índice de precipitação pluviométrica (Carvalho, 1986; Araujo et al., 2004; Oliveira et al., 2008). Portanto, escolheu-se como mês representativo do período "seco", outubro de 2007, e do período "chuvoso", março de 2008, para a realização das análises. Todas as amostras foram coletadas no intervalo de profundidade de $0,30 \mathrm{~m}$ a $0,35 \mathrm{~m}$, via trado manual. A forma de cada amostra era cilíndrica, com $0,05 \mathrm{~m}$ de altura e $0,02 \mathrm{~cm}$ de raio. A fim de minimizar o processo de perda de umidade, logo após as mesmas serem obtidas eram transportadas para o laboratório apropriado e realizadas as medidas de condutividade térmica, cujos resultados, foram obtidos com erro menor que $3 \%$.

Conforme Carvalho (1986) e Embrapa (1997), na cidade de Humaitá a precipitação pluviométrica anual varia de $2250 \mathrm{~mm}$ a $2750 \mathrm{~mm}$; a temperatura média anual varia de $24^{\circ} \mathrm{C}$ a $26^{\circ} \mathrm{C}$, enquanto que a umidade relativa do ar varia de $85 \%$ a $90 \%$. A drenagem na área estudada é eficiente.

\section{RESULTADOS E DISCUSSÃO}

\section{Variações de temperatura com a profundidade em local sem cobertura vegetal}

Os resultados apresentados a seguir foram obtidos em local sem cobertura vegetal, na cidade de Humaitá-AM.

Os valores diários da temperatura para o mês representativo do período "chuvoso", às $18 \mathrm{~h}$, às profundidades de $0,02 \mathrm{~m}$, 


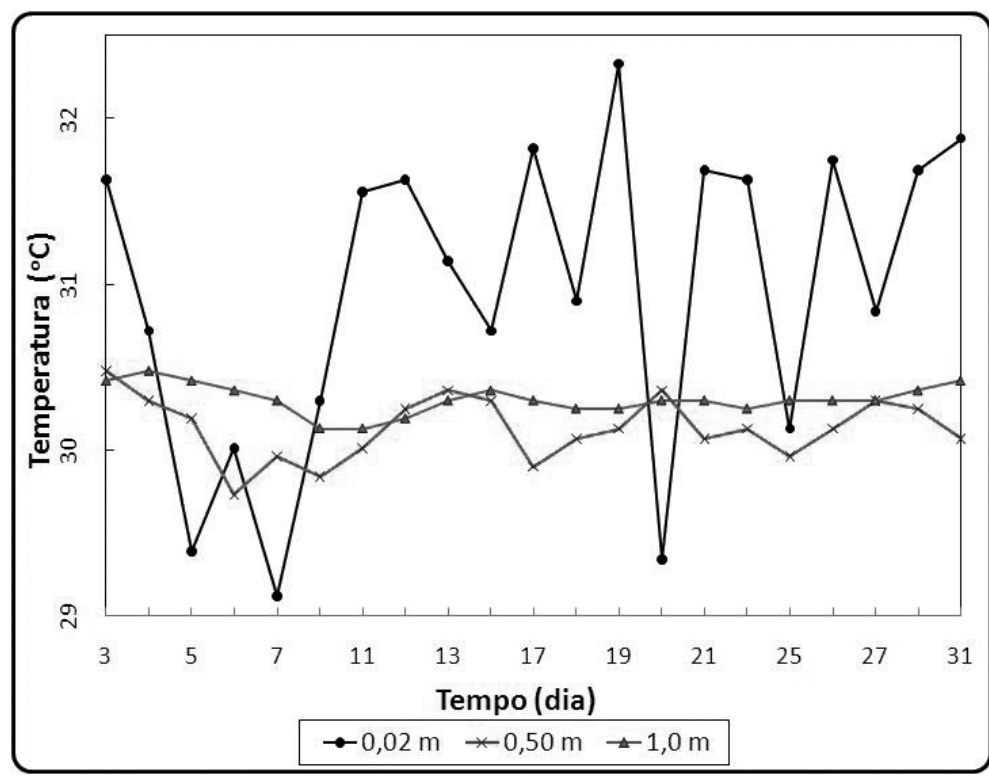

Figura 1 - Valores diários da temperatura, no mês de março de 2008, às $18 \mathrm{~h}$, às profundidades de $0,02 \mathrm{~m}, 0,5 \mathrm{~m}$ e $1,0 \mathrm{~m}$, em local sem cobertura vegetal.

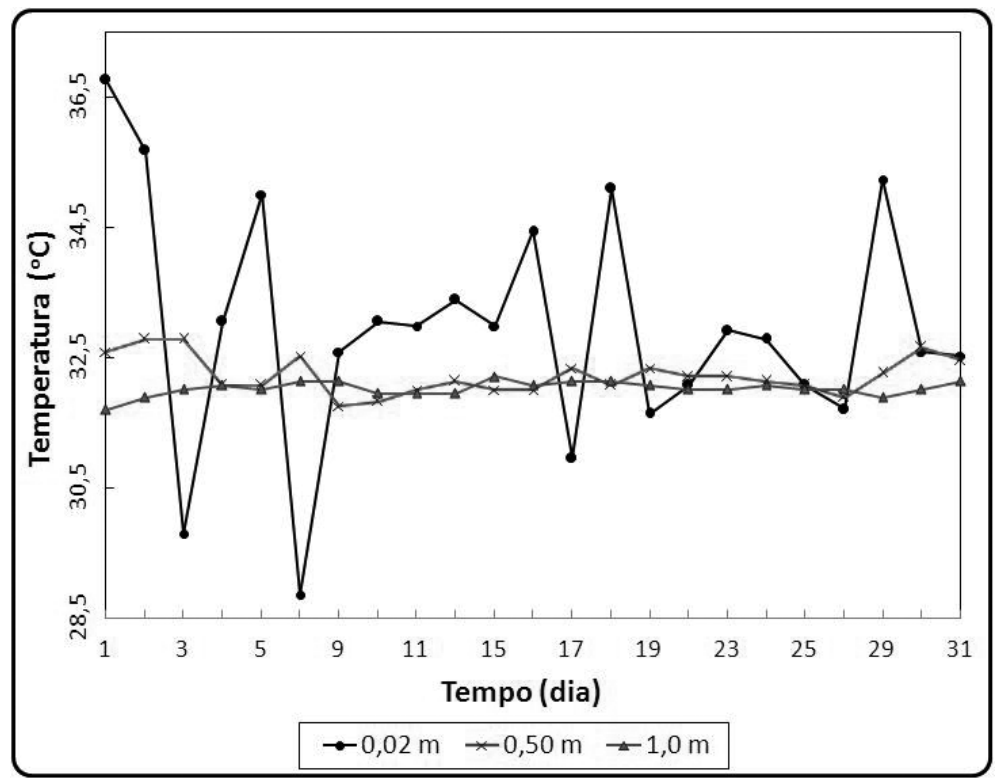

Figura 2 - Valores diários da temperatura, no mês de outubro de 2007, às $18 \mathrm{~h}$, às profundidades de $0,02 \mathrm{~m}, 0,5 \mathrm{~m} \mathrm{e} 1,0 \mathrm{~m}$, em local sem cobertura vegetal.

0,5 m 1,0 m, são mostrados na Figura 1, enquanto que a Figura 2 mostra os valores diários da temperatura para o período "seco", no mesmo horário e nas mesmas profundidades. Os valores máximo (dia 04) e mínimo (dias 10 e 11) da temperatura diária a 1,0 $\mathrm{m}$ de profundidade, registrados no mês de março, foram de $30,48^{\circ} \mathrm{C}$ e $30,13^{\circ} \mathrm{C}$, respectivamente. Dessa forma, foi registrada variação de $0,35^{\circ} \mathrm{C}$. Enquanto que para 0 mês de outubro os valores máximo e mínimo foram de $32,20^{\circ} \mathrm{C}$ e $31,69^{\circ} \mathrm{C}$, respectivamente, sendo que o valor máximo foi obtido no dia 15 e o mínimo no dia 01 . Assim, a variação registrada foi de $0,51^{\circ} \mathrm{C}$, à profundidade de $1,0 \mathrm{~m}$. Verifica-se que as magnitudes da temperatura à profundidade de $1,0 \mathrm{~m}$ são mais elevadas no período "seco" do que no período "chuvoso", como era de se esperar. 


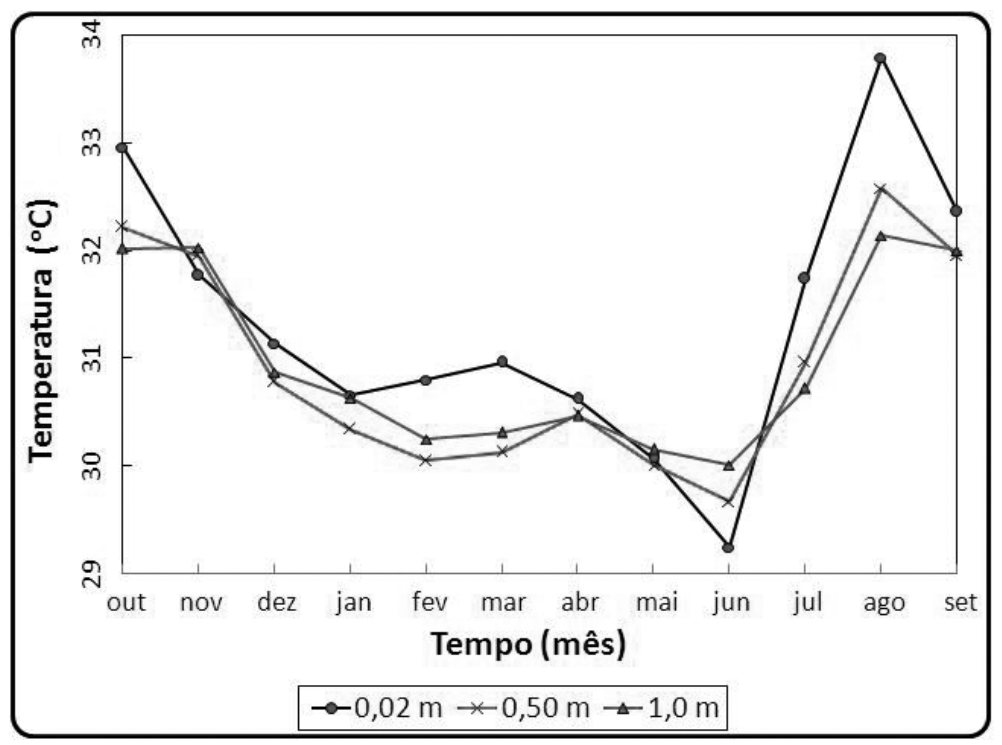

Figura 3 - Valores médios mensais da temperatura, no período de outubro de 2007 a setembro de 2008, às $18 \mathrm{~h}$, às profundidades de $0,02 \mathrm{~m}, 0,5 \mathrm{~m} \mathrm{e} \mathrm{1,0} \mathrm{m}$, em local sem cobertura vegetal.

Ainda nas Figuras 1 e 2 observa-se que para a profundidade de 0,5 m, no período "chuvoso", os valores máximo e mínimo foram de $30,48^{\circ} \mathrm{C}$ e $29,73^{\circ} \mathrm{C}$, respectivamente, registrados nos dias 03 e 06 . A variação desses valores foi de $0,75^{\circ} \mathrm{C}$. No período "seco", o valor máximo registrado foi de $32,78^{\circ} \mathrm{C}$ nos dias 02 e 03 , enquanto que 0 valor mínimo foi de $31,75^{\circ} \mathrm{C}$ registrado no dia 09 ; a variação medida foi de $1,03^{\circ} \mathrm{C}$.

No período "chuvoso", os valores máximo e mínimo, à profundidade de $0,02 \mathrm{~m}$, foram de $32,33^{\circ} \mathrm{C}$ e $29,12^{\circ} \mathrm{C}$, respectivamente, medidos nos dias 19 e 07 . A variação entre esses valores foi de $3,21^{\circ} \mathrm{C}$. Enquanto que no período "seco", o valor máximo foi de $36,76^{\circ} \mathrm{C}$, registrado no dia 01 , e 0 valor mínimo foi de $28,85^{\circ} \mathrm{C}$, registrado no dia 08 . A variação entre o valor máximo e mínimo foi de $7,91^{\circ} \mathrm{C}$.

Para ratificar esses resultados mostra-se a Figura $3 \mathrm{com}$ os valores médios mensais do período analisado, às $18 \mathrm{~h}$. A 0,02 $\mathrm{m}$ de profundidade, no mês de março, 0 valor médio mensal da temperatura foi de $30,96^{\circ} \mathrm{C}$, enquanto que no mês de outubro foi de $32,96^{\circ} \mathrm{C}$, portanto, houve diferença de $2,00^{\circ} \mathrm{C}$. À profundidade de $0,5 \mathrm{~m}, 0$ valor médio mensal da temperatura foi de $30,13^{\circ} \mathrm{C}$, para 0 mês de março e de $32,22^{\circ} \mathrm{C}$ para 0 mês de outubro, consequentemente, a variação registrada foi de $2,09^{\circ} \mathrm{C}$. Já para a profundidade de $1,0 \mathrm{~m}, 0$ valor médio mensal da temperatura foi de $30,31^{\circ} \mathrm{C}$, para 0 mês de março e de $32,02^{\circ} \mathrm{C}$ para 0 mês de outubro, consequentemente, a variação registrada foi de $1,71^{\circ} \mathrm{C}$. Fica em evidência que as variações ocorridas a 0,5 m e 1,0 m de profundidade são decorrências diretas das variações da temperatura a $0,02 \mathrm{~m}$ de profundidade.

A Figura 3 mostra que há variações significativas nos valores da temperatura às profundidades estudadas. Este comportamento não é característica somente das $18 \mathrm{~h}$, mas permanece para todos os horários estudados, conforme pode ser observado na Figura 4, a qual mostra os valores médios da temperatura às $13 \mathrm{~h}$.

Fato interessante que ocorre na cidade de Humaitá-AM é que às $18 \mathrm{~h}$, à profundidade de $0,02 \mathrm{~m}$, os valores das magnitudes da temperatura, tanto diários como médios, permanecem elevados em relação aos outros horários do dia, durante todo período estudado. Isto é verificado comparando-se as magnitudes da temperatura nas Figuras 3 e 4, e também, considerandose que nesse horário, normalmente, os valores de temperatura deveriam começar a diminuir, como ocorre em outras localidades, por exemplo, na cidade de Manaus, conforme mostra 0 trabalho de Araujo (1999). Em geral, nesse horário, a quantidade de energia solar incidente diminui e a quantidade de energia liberada pela superfície terrestre supera a incidente. Portanto, há outros fatores operantes, tais como pressão atmosférica e umidade, que devem estar contribuindo para esse acontecimento. No entanto, não há dados climatológicos do local disponíveis para o período estudado.

Também nas Figuras 3 e 4 nota-se que para as profundidades referenciadas, a diferença medida entre os valores da tempe- 


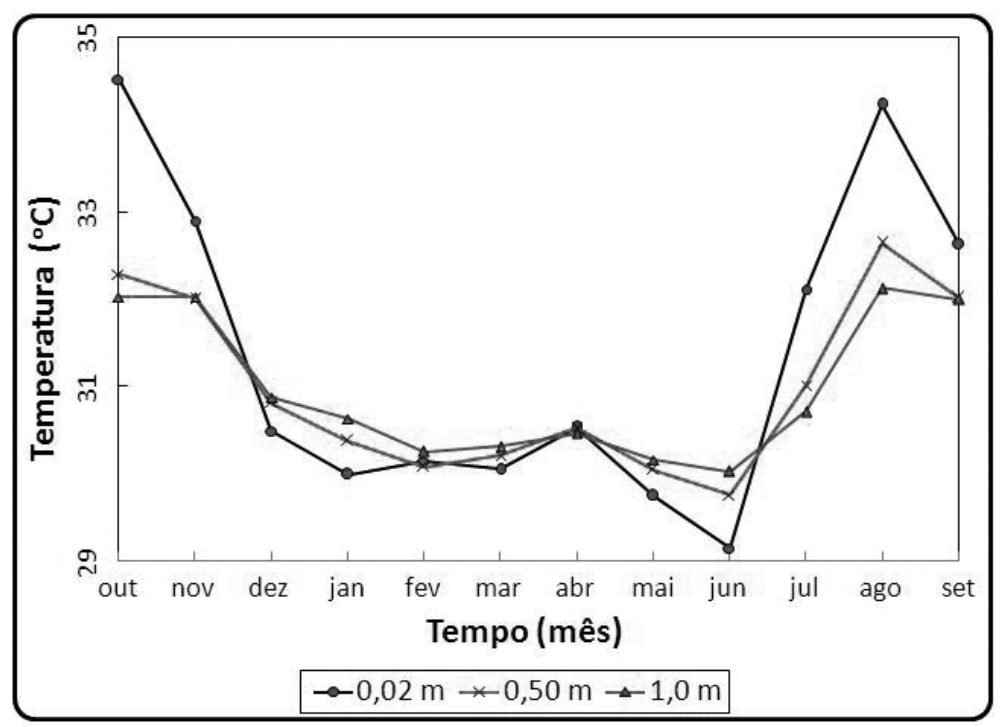

Figura 4 - Valores médios mensais da temperatura, no período de outubro de 2007 a setembro de 2008, às $13 \mathrm{~h}$, às profundidades de $0,02 \mathrm{~m}, 0,5 \mathrm{~m} \mathrm{e} \mathrm{1,0} \mathrm{m}$, em local sem cobertura vegetal.

ratura no período "chuvoso" foi de $0,60^{\circ} \mathrm{C}$ às $13 \mathrm{~h}$ e de $0,65^{\circ} \mathrm{C}$ às $18 \mathrm{~h}$. Já no período "seco" a diferença foi de $2,49^{\circ} \mathrm{C}$ às $13 \mathrm{~h} \mathrm{e}$ de $0,94^{\circ} \mathrm{C}$ às $18 \mathrm{~h}$.

\section{Variações de temperatura com a profundidade em local com cobertura vegetal}

Os resultados mostrados neste tópico foram obtidos em local com cobertura vegetal, situado a $25 \mathrm{~m}$ do local sem cobertura vegetal. A cobertura é composta por plantas arbóreas, sendo Ingá sp (ingazeira) e Mangifera indica (mangueira). Este tipo de vegetação é característico de toda a região Amazônica, no entanto, pelo fato da cidade de Humaitá ter sido submetida a intenso processo de desmatamento, a cobertura vegetal do local pesquisado não se constitui de vegetação primária, a qual se caracteriza por árvores de maior porte e exuberância.

Os valores de temperatura no local com cc, referentes ao mês de março de 2008, às 18 h, são apresentados na Figura 5. 0 valor máximo da temperatura diária a 1,0 $\mathrm{m}$ de profundidade foi de $27,95^{\circ} \mathrm{C}$, obtido nos dias 13 e 14 e o valor mínimo foi de $27,64^{\circ} \mathrm{C}$, obtido no dia 18 . Logo, a variação registrada foi de $0,31^{\circ} \mathrm{C}$. Para o mês de outubro, o valor máximo foi de $29,39^{\circ} \mathrm{C}$, obtido no dia 04 e 0 mínimo foi de $29,06^{\circ} \mathrm{C}$, nos dias 26 e 27. Portanto, a variação registrada foi de $0,33^{\circ} \mathrm{C}$, também à profundidade de $1,0 \mathrm{~m}$, às $18 \mathrm{~h}$, conforme mostra a Figura 6 .

À profundidade de $0,5 \mathrm{~m}$, no mês de março, 0 valor máximo foi de $27,79^{\circ} \mathrm{C}$, obtido nos dias 12,13 e 14 , e o valor mínimo foi de $27,48^{\circ} \mathrm{C}$, obtido nos dias 19 e 31, registrando variação de $0,31^{\circ} \mathrm{C}$. Enquanto que no mês de outubro o valor máximo foi de $29,56^{\circ} \mathrm{C}$, obtido no dia 03 , e o valor mínimo foi de $28,58^{\circ} \mathrm{C}$, obtido no dia 15. A variação entre esses valores foi de $0,98^{\circ} \mathrm{C}$.

No mês de março, a 0,02 $\mathrm{m}$ de profundidade, os valores máximo e mínimo foram de $27,74^{\circ} \mathrm{C}$, no dia 11 e de $26,79^{\circ} \mathrm{C}$, no dia 18 , respectivamente. A variação registrada foi de $0,95^{\circ} \mathrm{C}$. No mês de outubro, os valores máximo e mínimo foram de $29,73^{\circ} \mathrm{C}$ no dia 01 , e de $27,29^{\circ} \mathrm{C}$ no dia 03 , respectivamente. A variação registrada foi de $2,44^{\circ} \mathrm{C}$. Observa-se, novamente, que há relação direta entre a variação dos valores da temperatura a $0,02 \mathrm{~m} \mathrm{e} \mathrm{a}$ $1,0 \mathrm{~m}$ de profundidade.

A Figura 7 mostra os valores médios mensais da temperatura às $18 \mathrm{~h}$, durante todo período estudado, no local com cc.

0 valor médio mensal da temperatura no mês de março, à profundidade de $0,02 \mathrm{~m}$, às $18 \mathrm{~h}$, foi de $27,27^{\circ} \mathrm{C}$, enquanto que no mês de outubro foi de $28,52^{\circ} \mathrm{C}$, portanto, houve diferença de $1,25^{\circ} \mathrm{C}$. À profundidade de $0,5 \mathrm{~m}, 0$ valor médio mensal da temperatura para o mês de março foi de $27,63^{\circ} \mathrm{C}$ e de $29,09^{\circ} \mathrm{C}$ para 0 mês de outubro, registrando diferença de $1,46^{\circ} \mathrm{C}$. Já para a profundidade de $1,0 \mathrm{~m}, 0$ valor médio mensal da temperatura foi de $27,78^{\circ} \mathrm{C}$, para o mês de março e de $29,18^{\circ} \mathrm{C}$ para o mês de outubro, consequentemente, a variação registrada foi de $1,40^{\circ} \mathrm{C}$.

Nota-se que a diferença dos valores médios mensais da temperatura no período "seco" é mensuravelmente maior no local sc, visto no item anterior, do que no local cc. Com esse resultado quantifica-se e verifica-se a importância da cobertura vegetal para a região em estudo. 


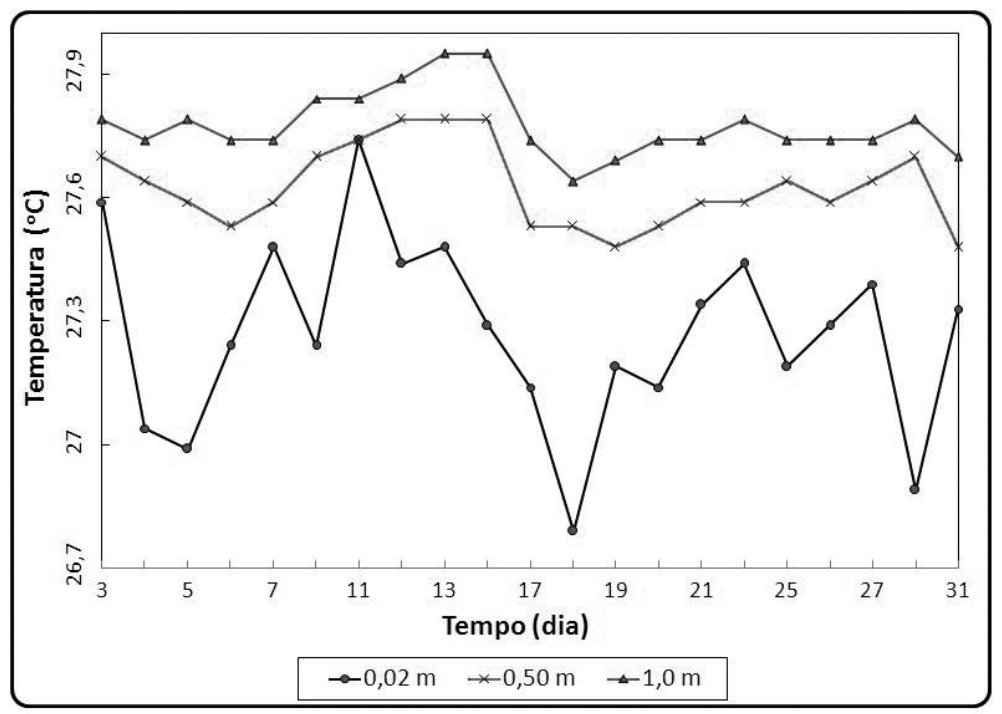

Figura 5 - Valores diários da temperatura, no mês de março de 2008, às 18 h, às profundidades de $0,02 \mathrm{~m}, 0,5 \mathrm{~m}$ e 1,0 m, em local com cobertura vegetal.

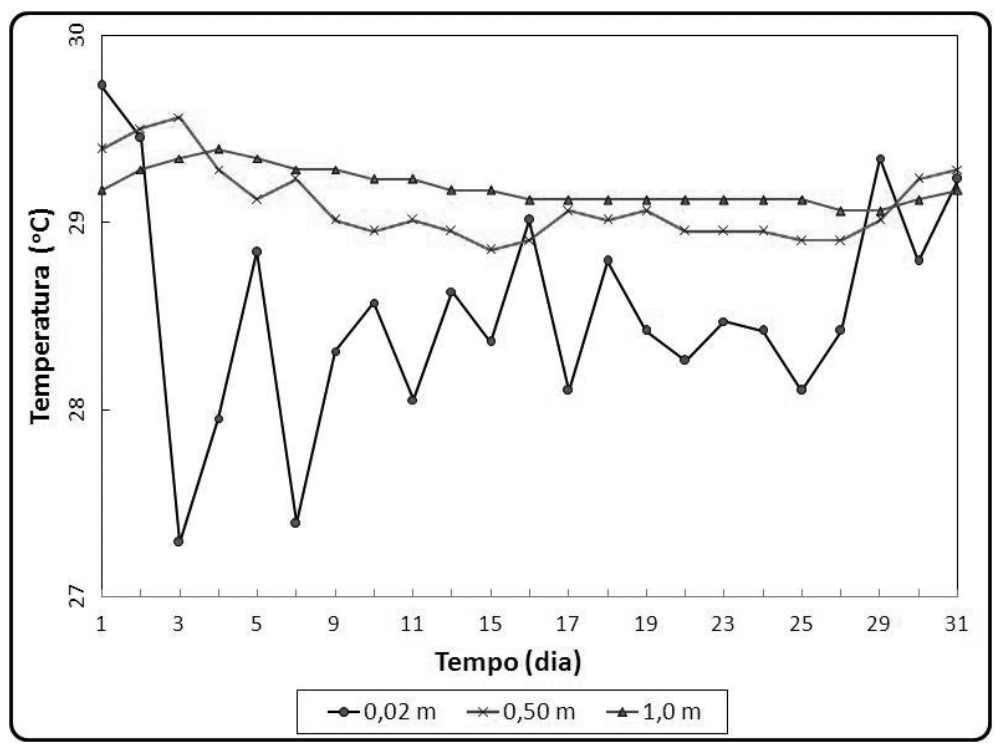

Figura 6 - Valores diários da temperatura, no mês de outubro de 2007, às $18 \mathrm{~h}$, às profundidades de $0,02 \mathrm{~m}, 0,5 \mathrm{~m}$ e $1,0 \mathrm{~m}$, em local com cobertura vegetal.

Para mostrar que os valores de temperatura a $1,0 \mathrm{~m}$ de profundidade não podem ser negligenciados, apresenta-se as Figuras 8 e 9, referentes aos valores médios da temperatura nos horários das 13 h e 18 h, nos locais cc e sc, durante todo o período estudado. Observa-se que o comportamento das curvas para os três horários são similares, porém as variações são nitidamente observadas nos dois locais, ou sejam, cc e sc. As diferenças dos valores médios mensais da temperatura para 0 período "seco" entre os dois locais, foram de $2,83^{\circ} \mathrm{C}$ às $8 \mathrm{~h}$, $2,84^{\circ} \mathrm{C}$ às $13 \mathrm{~h} \mathrm{e} \mathrm{de} 2,84^{\circ} \mathrm{C}$ às $18 \mathrm{~h}$. Para o período "chuvoso" as diferenças registradas entre os valores médios mensais da temperatura foram de $2,51^{\circ} \mathrm{C}$ às $8 \mathrm{~h}, 2,51^{\circ} \mathrm{C}$ às $13 \mathrm{~h}$ e de $2,53^{\circ} \mathrm{C}$ às $18 \mathrm{~h}$. Portanto, há diferença pelo fato de um local possuir cobertura vegetal e outro não e a propagação do fluxo termal persiste a $1,0 \mathrm{~m}$ de profundidade, tanto em local cc como em local sc, e é perfeitamente mensurável. 


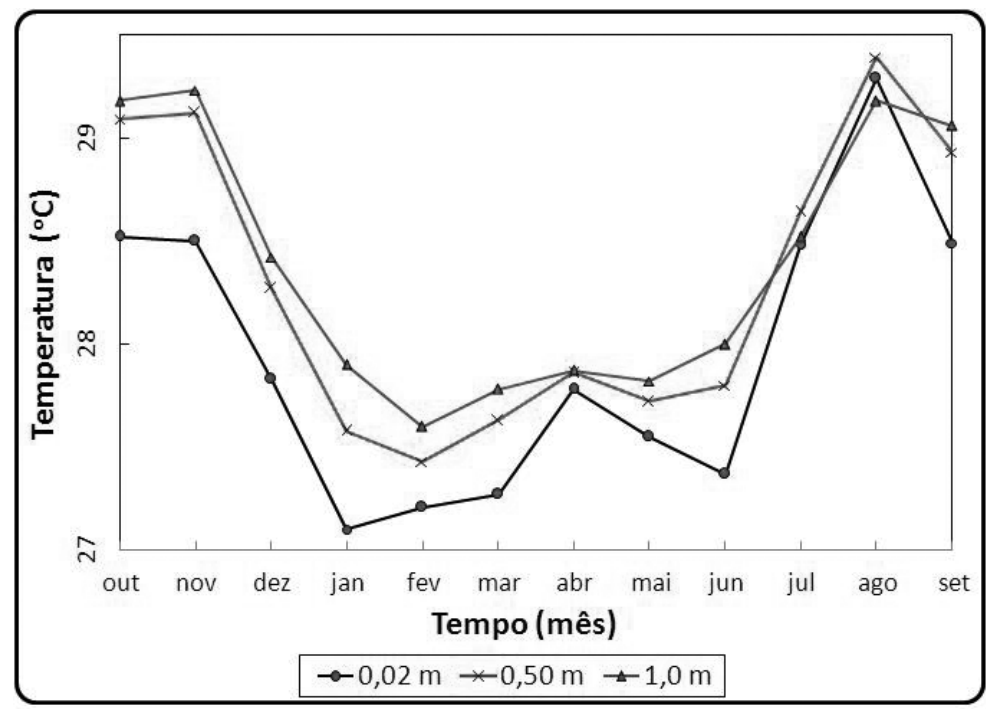

Figura 7 - Valores médios mensais da temperatura, no período de outubro de 2007 a setembro de 2008, às $18 \mathrm{~h}$, às profundidades de $0,02 \mathrm{~m}, 0,5 \mathrm{~m} \mathrm{e} 1,0 \mathrm{~m}$, em local com cobertura vegetal.

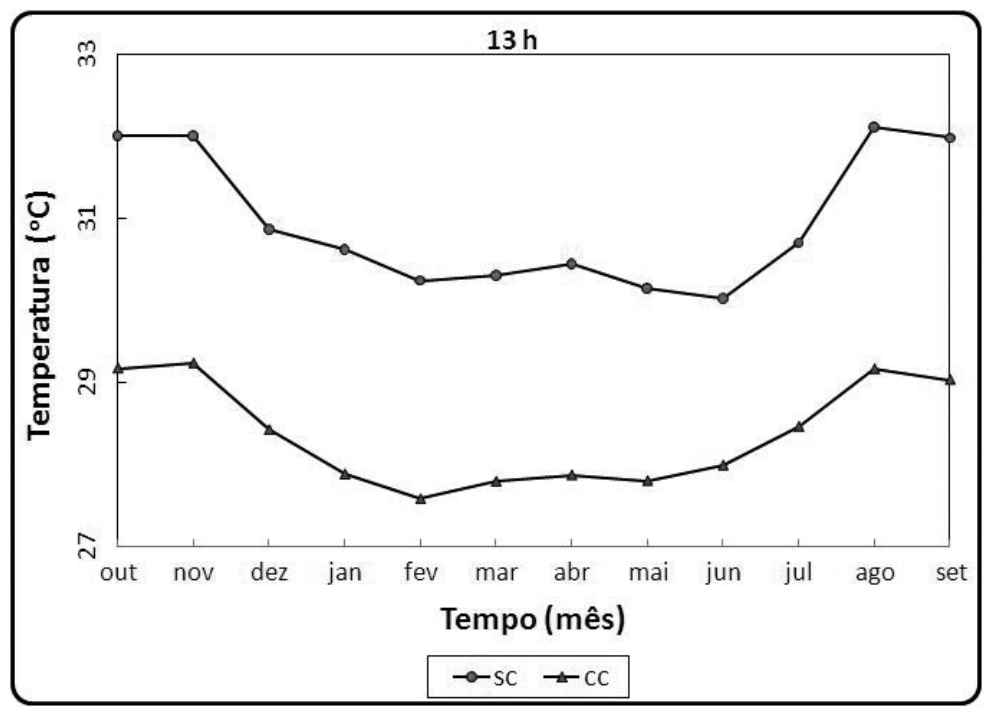

Figura 8 - Valores médios mensais da temperatura, no período de outubro de 2007 a setembro de 2008, às 13 h, a 1,0 m de profundidade, em locais com e sem cobertura vegetal.

\section{Variações de temperatura a $0,02 \mathrm{~m}$ de profundidade em locais com e sem cobertura vegetal}

Neste estudo, a profundidade de 0,02 m é considerada como sendo a superfície de incidência da radiação solar. A seguir, farse-á uma comparação entre os meses de março de 2008 e outubro de 2007, que são os meses representativos dos períodos "chuvoso" e "seco", respectivamente.

Em base nos valores diários da temperatura registrados no mês de março de 2008, no horário das 13 h, a 0,02 m de pro- fundidade, nos locais cc e sc, observa-se que há diferença significativa entre as magnitudes da temperatura. A Figura 10 mostra os valores diários da temperatura a $0,02 \mathrm{~m}$, registrada no mês de março de 2008, às 13 h, nos locais cc e sc. Nesta figura observase, nitidamente, a influência da cobertura vegetal superficial sobre o regime geotermal raso, o que é caracterizado pelo fato de que, no mesmo horário referencial, há elevada superioridade dos valores das temperaturas medidas no local sc, em relação aos valores referentes ao local cc. Neste mês, registrou-se valores máximos de $31,56^{\circ} \mathrm{C}$ e $27,59^{\circ} \mathrm{C}$, para os locais sc e cc, respec- 


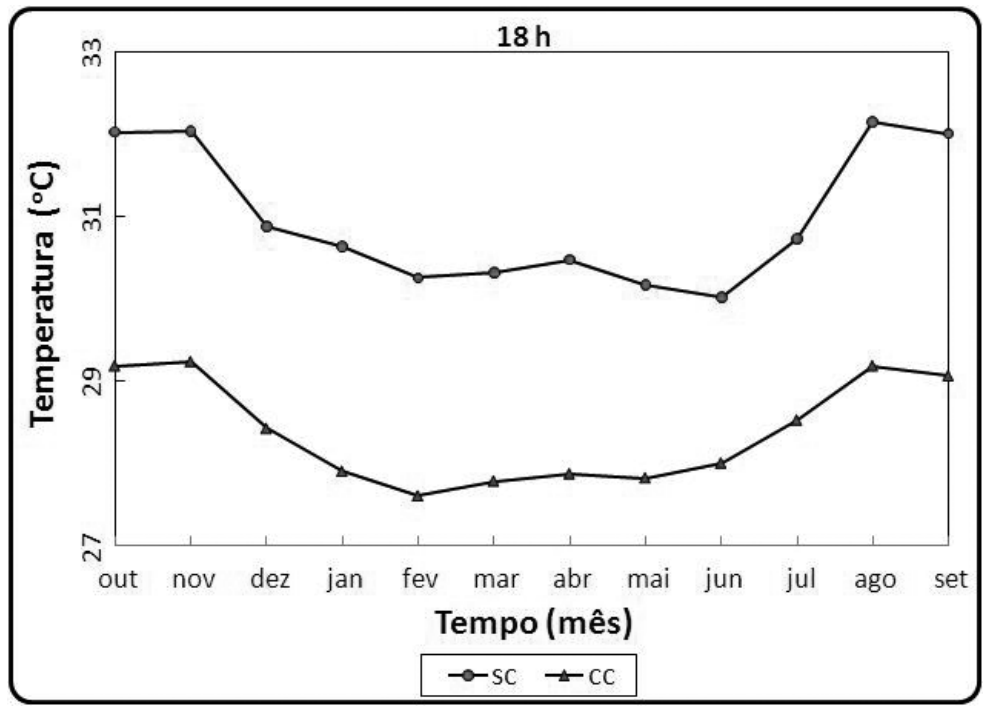

Figura 9 - Valores médios mensais da temperatura, no período de outubro de 2007 a setembro de 2008, às 18 h, a 1,0 m de profundidade, em locais com e sem cobertura vegetal.

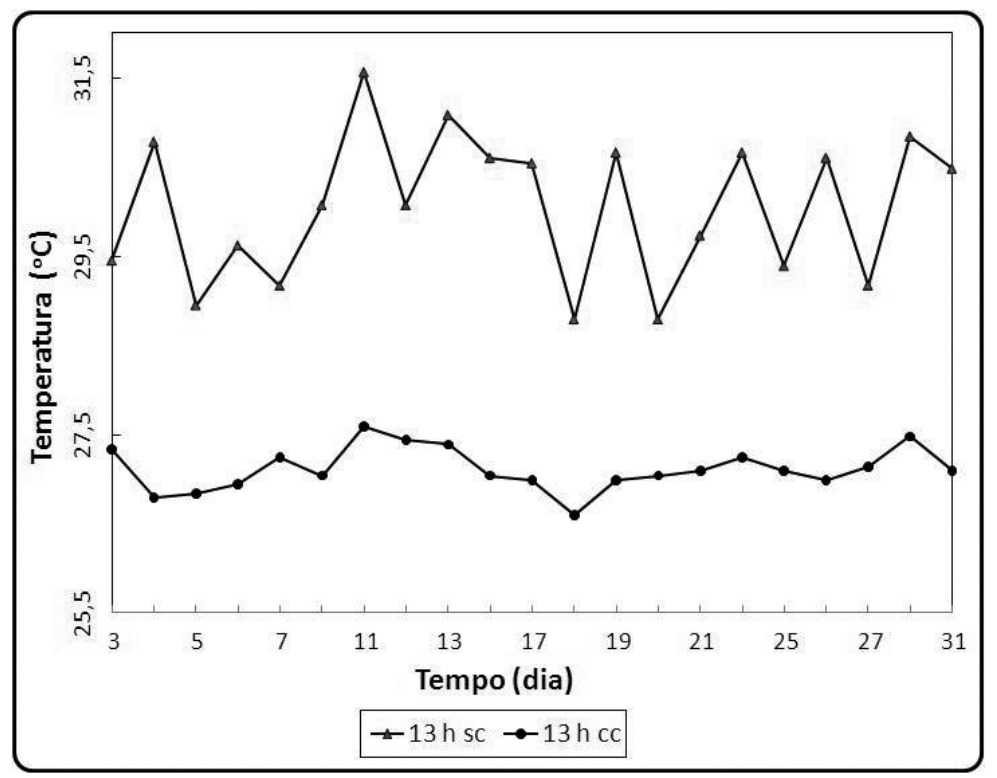

Figura 10 - Valores diários da temperatura a 0,02 m de profundidade, no mês de março de 2008, às $13 \mathrm{~h}$, nos locais com e sem cobertura vegetal.

tivamente, havendo, portanto, diferença de $3,97^{\circ} \mathrm{C}$, no dia 11 , e mínimos de $28,79^{\circ} \mathrm{C}$ e $26,60^{\circ} \mathrm{C}$, com diferença de $2,19^{\circ} \mathrm{C}$, no dia 18. 0 valor médio da temperatura diária para o mês de março de 2008, às $13 \mathrm{~h}$, foi de $30,05^{\circ} \mathrm{C}$ para o local sc e de $27,11^{\circ} \mathrm{C}$ para o local cc. Portanto, a diferença registrada entre as médias foi de $2,94^{\circ} \mathrm{C}$.

0 mesmo comportamento observa-se na Figura 11, referente ao mês de outubro de 2007, às 13 h, nos dois locais estu- dados. No mês de outubro, registrou-se valores máximos de $38,69^{\circ} \mathrm{C}$ e $29,56^{\circ} \mathrm{C}$, para os locais sc e Cc, respectivamente, com diferença de $9,63^{\circ} \mathrm{C}$, no dia 01 , e mínimos de $29,62^{\circ} \mathrm{C}$ e $27,39^{\circ} \mathrm{C}$, com diferença de $2,2^{\circ} \mathrm{C}$, no dia 26 . Portanto, há diferença de até $9,63^{\circ} \mathrm{C}$, simplesmente pelo fato de um dos locais não ter proteção da vegetação. 0 valor médio da temperatura diária foi de $34,51^{\circ} \mathrm{C}$ para o local sc e de $28,50^{\circ} \mathrm{C}$, para 0 local $\mathrm{cc}$, no mesmo horário, consequentemente, a diferença entre 


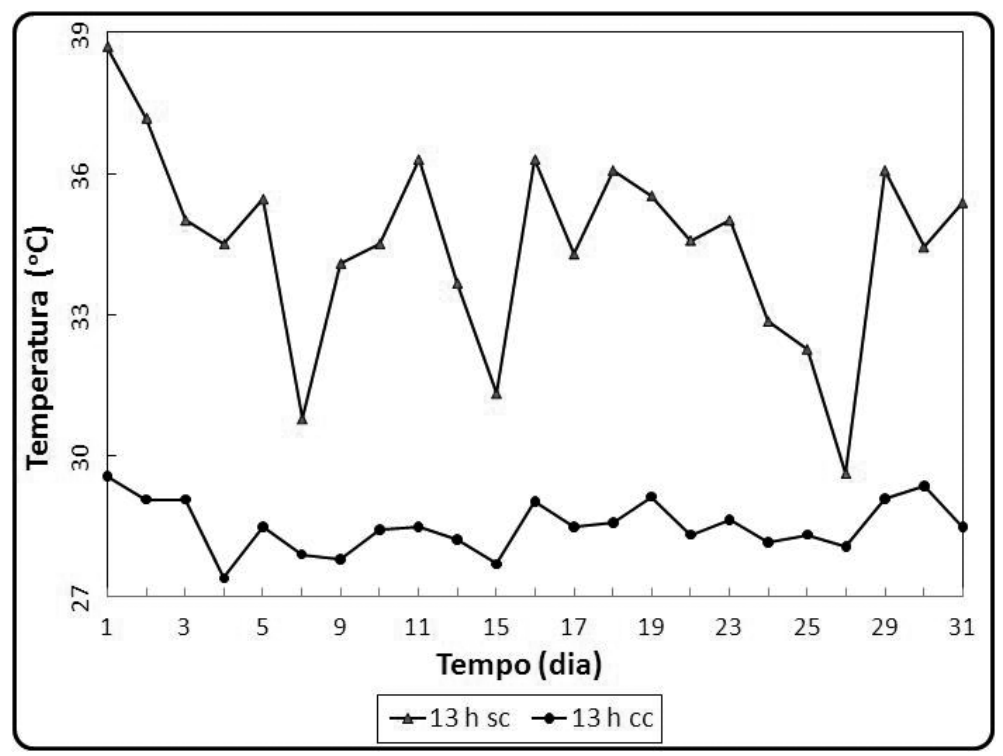

Figura 11 - Valores diários da temperatura a 0,02 m de profundidade, no mês de outubro de 2007, às $13 \mathrm{~h}$, nos locais com e sem cobertura vegetal.

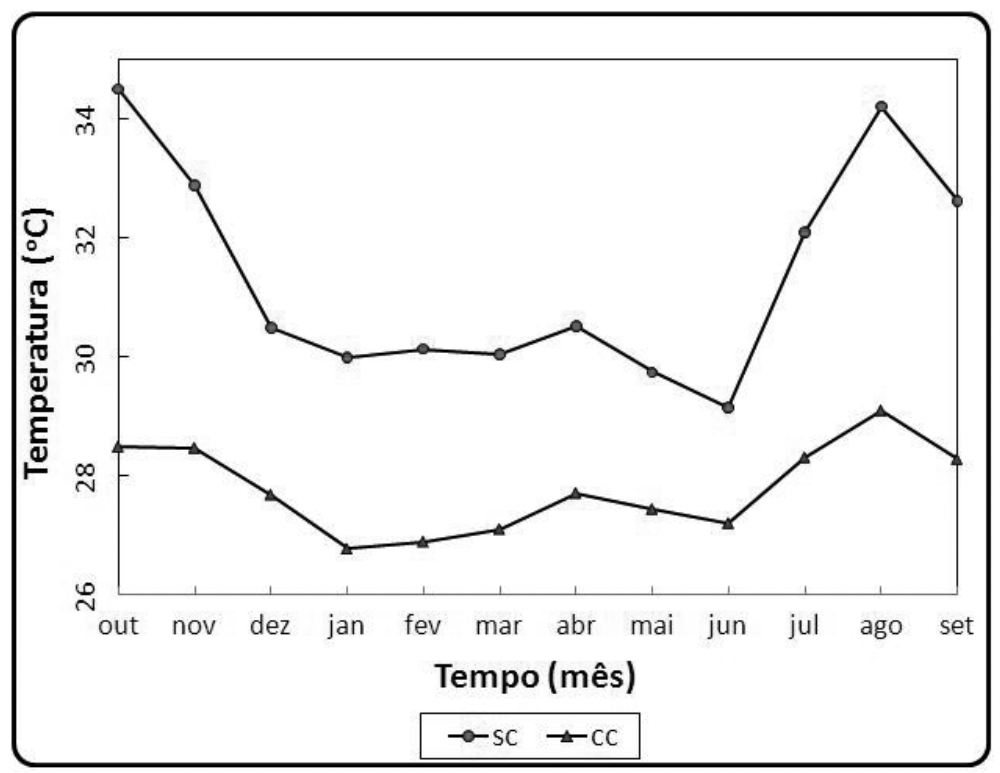

Figura 12 - Valores médios mensais da temperatura a 0,02 $\mathrm{m}$ de profundidade, no período de outubro de 2007 a setembro de 2008, às 13 h, nos locais com e sem cobertura vegetal.

as médias foi de $6,01^{\circ} \mathrm{C}$. Isto ratifica, portanto, a mensurável influência da cobertura vegetal nos valores de temperatura a $0,02 \mathrm{~m}$. Este resultado é de suma importância, pois quantifica a influência da cobertura vegetal no regime térmico de determinada região.

As variações mensuradas não são características somente dos meses referenciados, permanecendo ao longo de todo período estudado. Para ratificar esta afirmação, apresenta-se as Fi- guras 12 e 13, referentes aos valores médios mensais da temperatura durante o ciclo climático de um ano, nos dois locais, ou seja, cc e sc, nos diferentes horários.

Os dois locais apresentam a mesma litologia, então, pode-se dizer que a elevada diferença da variação nos valores da temperatura média mensal deve-se ao grau de proteção vegetal. Dessa forma, é possível mensurar a influência da cobertura vegetal no 


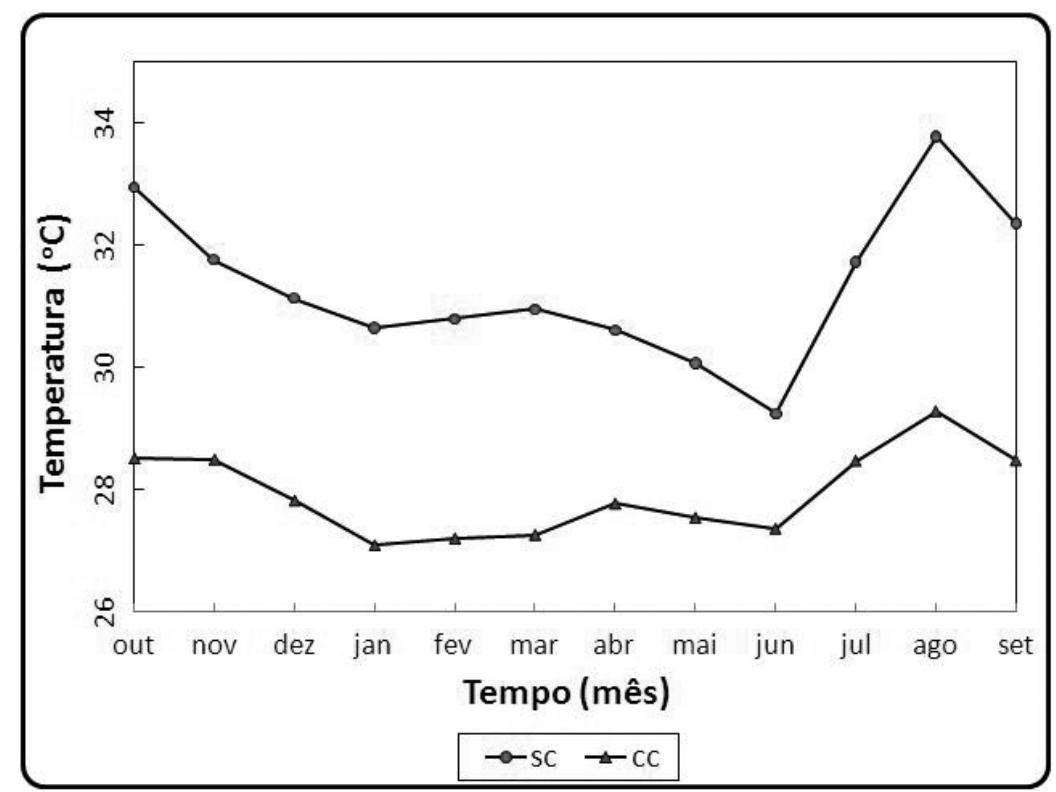

Figura 13 - Valores médios mensais da temperatura a 0,02 $\mathrm{m}$ de profundidade, no período de outubro de 2007 a setembro de 2008, às 18 h, nos locais com e sem cobertura vegetal.

regime geotermal raso. A temperatura média de todo ciclo estudado no local sc foi de $31,37^{\circ} \mathrm{C}$ às $13 \mathrm{~h}$ e de $31,34^{\circ} \mathrm{C}$ às $18 \mathrm{~h}$, enquanto que no local cc foi de $27,80^{\circ} \mathrm{C}$ às $13 \mathrm{~h}$ e de $27,95^{\circ} \mathrm{C}$ às $18 \mathrm{~h}$. As diferenças entre as médias foram de $3,57^{\circ} \mathrm{C}$ e de $3,39^{\circ} \mathrm{C}$ nos horários das 13 h e 18 h, respectivamente.

Observa-se também, nas Figuras 12 e 13, que os valores de temperatura média para o mês de junho têm maior decréscimo no local sc. Uma das explicações para isso, deve-se ao fato de que no período de 31 de maio a 04 de junho ocorreu na região estudada o fenômeno que é comumente denominado de "friagem", provocado pelo deslocamento de massa de ar polar atlântica.

\section{Variações de condutividade térmica}

0 estudo do fluxo de calor em determinada área exige a determinação precisa da condutividade térmica. Segundo Beck (1965), essa exigência deve-se ao fato de que 0 fluxo geotérmico em situações de estratificação plana pode ser definido pelo produto dos parâmetros de gradiente de temperatura e condutividade térmica, representativos da área em estudo. Conforme mencionado anteriormente, foram realizadas medidas de condutividade térmica em amostras de solo coletadas no intervalo de profundidade de 0,30 m a 0,35 m, nos meses de março e outubro, meses representativos dos períodos "chuvoso" e "seco". A escolha destes meses como, também, o procedimento para a obtenção dos valores de condutividade térmica, estão descritos nos procedimentos metodológicos.

Os valores obtidos foram de $0,54 \mathrm{~W} / \mathrm{m}^{\circ} \mathrm{C}$ para 0 período "seco" e de 1,23 W/m C para o período "chuvoso"; a porcentagem de água obtida nas amostras foram de 2,76\% para o período "seco" e de 3,98\% para o período "chuvoso".

Os resultados acima apresentados ratificam que a condutividade térmica varia com o conteúdo de água existente na amostra. Para comprovar tal afirmação, foi realizado um experimento em laboratório, para analisar o comportamento da condutividade térmica em função da porcentagem de água existente na amostra de solo. Os resultados obtidos são mostrados na Figura 14. Observa-se que há grande variação dos valores de condutividade térmica com 0 conteúdo de água adicionado à amostra. Verifica-se que após se adicionar $100 \mathrm{ml}$ de água, a amostra atinge 0 estado de saturação. Da mesma forma que a variação da condutividade térmica foi verificada nesse experimento, também ocorre naturalmente na região em estudo, sendo que o conteúdo de água é variável e depende de fonte externa, ou seja, da precipitação pluviométrica local.

Nos estudos de geotermia rasa há variações significativas nos valores de condutividade térmica em pequenas profundidades, por isso é importante tomar cuidado com o uso dos valores desse parâmetro físico disponível na literatura, pois nem sempre a amostra está saturada e sua origem pode ser de locais com características ambientais diferentes. Desta forma para obter me- 


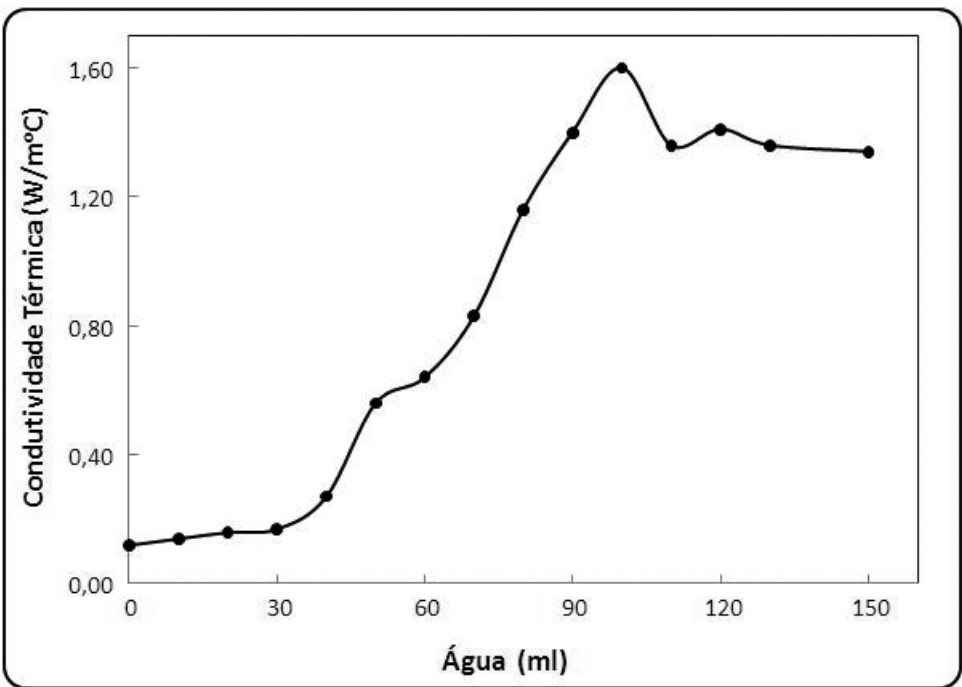

Figura 14 - Valores de condutividade térmica em função da porcentagem de água, em amostra de solo, referente ao período "chuvoso".

Ihor precisão no cálculo do fluxo geotérmico é necessário medir a condutividade térmica do material do local em estudo.

\section{Variações do fluxo geotermal raso a $0,5 \mathrm{~m}$ e a $1,0 \mathrm{~m}$ de profundidade}

0 valor médio do fluxo geotermal profundo ao longo da superfície da Terra não é homogêneo. Desde os anos 60 tem-se compilado as várias medidas de fluxo geotérmico efetuadas ao longo do globo, observando-se diferentes valores para o fluxo de calor nos continentes, fluxo de calor nas zonas de subducção e assim para cada região estudada.

Os resultados de trabalhos realizados na região Amazônica mostram, pequenas diferenças entre os valores médios do fluxo geotérmico profundo para os diversos locais estudados: No trabalho de Araujo (1987) foi obtido o valor de $42,16 \mathrm{~mW} / \mathrm{m}^{2}$, para a região metropolitana de Belém-PA, enquanto que no trabalho de Carvalho et al. (1986) obteve-se o valor de $44,00 \mathrm{~mW} / \mathrm{m}^{2}$, para a Bacia do Médio Amazonas; já no trabalho de Araujo (1999), foi obtido 0 valor de $44,91 \mathrm{~mW} / \mathrm{m}^{2}$ para a cidade de Manaus-AM. Dessa forma, neste trabalho, toma-se como referência para efeito de análises o valor médio do fluxo geotermal profundo obtido por Araujo (1999) em Manaus-AM, que é a região mais próxima dos locais estudados.

As Tabelas 1 e 2 apresentam os valores mensais do fluxo geotermal raso às $13 \mathrm{~h}$, a $0,5 \mathrm{~m}$ e a $1,0 \mathrm{~m}$ de profundidade, nos locais sc e cc, respectivamente, e também, apresenta os valores do gradiente de temperatura. Para a condutividade térmica foram utilizados os valores representativos dos períodos "seco" e "chuvoso".

A Figura 15 mostra os resultados dos valores do fluxo geotermal raso a $0,5 \mathrm{~m}$ de profundidade, às $13 \mathrm{~h}$, nos locais sc e cc.

Os valores absolutos mínimo e máximo do fluxo geotermal a $0,5 \mathrm{~m}$ de profundidade às $13 \mathrm{~h}$, no local sc foram de $0,03 \mathrm{~W} /$ $\mathrm{m}^{2}$ e de $2,51 \mathrm{~W} / \mathrm{m}^{2}$, respectivamente. Considerando em termos absolutos, esses valores representam aproximadamente $66,8 \mathrm{a}$ $5,6 \times 10^{3}$ acima do valor do fluxo geotermal profundo na região estudada, que é de 44,91 mW/m² , obtido por Araujo (1999). Já para o local cc, os valores foram de $0,33 \mathrm{~W} / \mathrm{m}^{2}$ para 0 valor mínimo e de 2,10 W/m² para o valor máximo, o que representa em termos absolutos de 734,8 a 4,7×103 acima do valor médio do fluxo profundo na região em estudo. A variação entre os valores máximo e mínimo no local sc foi de $2,48 \mathrm{~W} / \mathrm{m}^{2}$, enquanto que no local cc foi de $1,77 \mathrm{~W} / \mathrm{m}^{2}$, o que representa $3,4 \times 10^{3} \mathrm{e}$ $3,9 \times 10^{3}$ acima do valor médio do fluxo térmico terrestre local.

0 valor médio do fluxo geotemal raso, no local sc, foi de $-0,31 \mathrm{~W} / \mathrm{m}^{2}$, e de $0,91 \mathrm{~W} / \mathrm{m}^{2}$ no local cc, portanto, registrou-se variação de $0,60 \mathrm{~W} / \mathrm{m}^{2}$; 0 que representa em termos absolutos, $1,3 \times 10^{3}$ acima do valor médio do fluxo profundo na região. 0 sinal negativo indica que o fluxo geotérmico flui no sentido das camadas de menor para as de maior profundidade, o que ocorre na maior parte do período estudado no local sc. Nota-se que esses resultados são extremamente elevados em relação ao valor médio do fluxo geotermal profundo, portanto, há mensurável influência da fonte externa no regime geotermal raso local. 
Tabela 1 - Valores mensais do fluxo geotermal a 0,5 m e 1,0 $\mathrm{m}$ de profundidade, às $13 \mathrm{~h}$, para o local sem cobertura vegetal.

\begin{tabular}{|l|c|c|c|c|}
\hline \multirow{2}{*}{ Tempo (mês) } & \multicolumn{2}{|c|}{$0,5 \mathrm{~m}$} & \multicolumn{2}{c|}{$1,0 \mathrm{~m}$} \\
\cline { 2 - 5 } & $\mathrm{G}\left({ }^{\circ} \mathrm{C} / \mathrm{m}\right)$ & $\mathrm{Q}\left(\mathrm{W} / \mathrm{m}^{2}\right)$ & $\mathrm{G}\left({ }^{\circ} \mathrm{C} / \mathrm{m}\right)$ & $\mathrm{Q}\left(\mathrm{W} / \mathrm{m}^{2}\right)$ \\
\hline Outubro/2007 & $-4,65$ & $-2,51$ & $-0,52$ & $-0,28$ \\
Novembro/2007 & $-1,85$ & $-1,00$ & 0,04 & 0,02 \\
Dezembro/2007 & 0,67 & 0,82 & 0,12 & 0,15 \\
Janeiro/2008 & 0,79 & 0,97 & 0,52 & 0,64 \\
Fevereiro/2008 & $-1,13$ & $-0,15$ & 0,34 & 0,42 \\
Março/2008 & 0,33 & 0,41 & 0,20 & 0,25 \\
Abril/2008 & $-0,02$ & $-0,03$ & $-0,12$ & $-0,15$ \\
Maio/2008 & 0,60 & 0,74 & 0,24 & 0,30 \\
Junho/2008 & 1,27 & 0,69 & 0,54 & 0,29 \\
Julho/2008 & $-2,29$ & $-1,24$ & $-0,60$ & $-0,32$ \\
Agosto/2008 & $-3,29$ & $-1,78$ & $-1,04$ & $-0,56$ \\
Setembro/2008 & $-1,27$ & $-0,69$ & $-0,04$ & $-0,02$ \\
\hline
\end{tabular}

Tabela 2 - Valores mensais do fluxo geotermal a 0,5 m e a 1,0 m de profundidade, às $13 \mathrm{~h}$, para o local com cobertura vegetal.

\begin{tabular}{|l|c|c|c|c|}
\hline \multirow{2}{*}{ Tempo (mês) } & \multicolumn{2}{|c|}{$0,5 \mathrm{~m}$} & \multicolumn{2}{c|}{$1,0 \mathrm{~m}$} \\
\cline { 2 - 5 } & $\mathrm{G}\left({ }^{\circ} \mathrm{C} / \mathrm{m}\right)$ & $\mathrm{Q}\left(\mathrm{W} / \mathrm{m}^{2}\right)$ & $\mathrm{G}\left({ }^{\circ} \mathrm{C} / \mathrm{m}\right)$ & $\mathrm{Q}\left(\mathrm{W} / \mathrm{m}^{2}\right)$ \\
\hline Outubro/2007 & 1,25 & 0,68 & 0,16 & 0,09 \\
Novembro/2007 & 1,38 & 0,74 & 0,20 & 0,11 \\
Dezembro/2007 & 1,25 & 1,54 & 0,28 & 0,34 \\
Janeiro/2008 & 1,71 & 2,1 & 0,58 & 0,71 \\
Fevereiro/2008 & 1,08 & 1,33 & 0,34 & 0,42 \\
Março/2008 & 1,10 & 1,36 & 0,32 & 0,39 \\
Abril/2008 & 0,27 & 0,27 & 0,06 & 0,33 \\
Maio/2008 & 0,56 & 0,69 & 0,18 & 0,22 \\
Junho/2008 & 1,27 & 0,69 & 0,36 & 0,19 \\
Julho/2008 & 0,67 & 0,38 & $-0,34$ & $-0,18$ \\
Agosto/2008 & 0,60 & 0,33 & $-0,46$ & $-0,25$ \\
Setembro/2008 & 1,40 & 0,75 & 0,16 & 0,09 \\
\hline
\end{tabular}

A Figura 16 apresenta os resultados dos valores do fluxo geotermal raso, às $13 \mathrm{~h}$, a 1,0 $\mathrm{m}$ de profundidade, para os locais sc e cc.

Os valores absolutos mínimo e máximo do fluxo geotermal a $1,0 \mathrm{~m}$ de profundidade, às $13 \mathrm{~h}$, no local sc foram de $0,02 \mathrm{~W} / \mathrm{m}^{2} \mathrm{e}$ de $0,64 \mathrm{~W} / \mathrm{m}^{2}$, respectivamente. Considerando em termos absolutos, 0 valor mínimo representa 44,49 acima do valor médio do fluxo profundo na região, e 0 valor máximo representa $1,4 \times 10^{3}$ acima desse valor. Para o local cc, os valores foram de 0,09 W/ $\mathrm{m}^{2}$ para 0 valor mínimo e de $0,71 \mathrm{~W} / \mathrm{m}^{2}$ para 0 valor máximo.
0 valor mínimo representa em termos absolutos 200,40 acima do valor médio do fluxo profundo, e o valor máximo representa $1,6 \times 10^{3}$ acima deste mesmo valor. A variação entre os valores máximo e o mínimo no local sc foi de $0,62 \mathrm{~W} / \mathrm{m}^{2}$, enquanto que no local cc também foi de $0,62 \mathrm{~W} / \mathrm{m}^{2}$, ambos representando $1,4 \times 10^{3}$ acima do valor médio do fluxo profundo terrestre local.

0 valor médio do fluxo geotemal raso no local sc foi de $-0,06 \mathrm{~W} / \mathrm{m}^{2}$ e de $0,21 \mathrm{~W} / \mathrm{m}^{2}$ no local cc, portanto, registrouse variação de $0,15 \mathrm{~W} / \mathrm{m}^{2}$. Isso representa em termos absolutos, 334,0 acima do valor médio do fluxo profundo na região. 


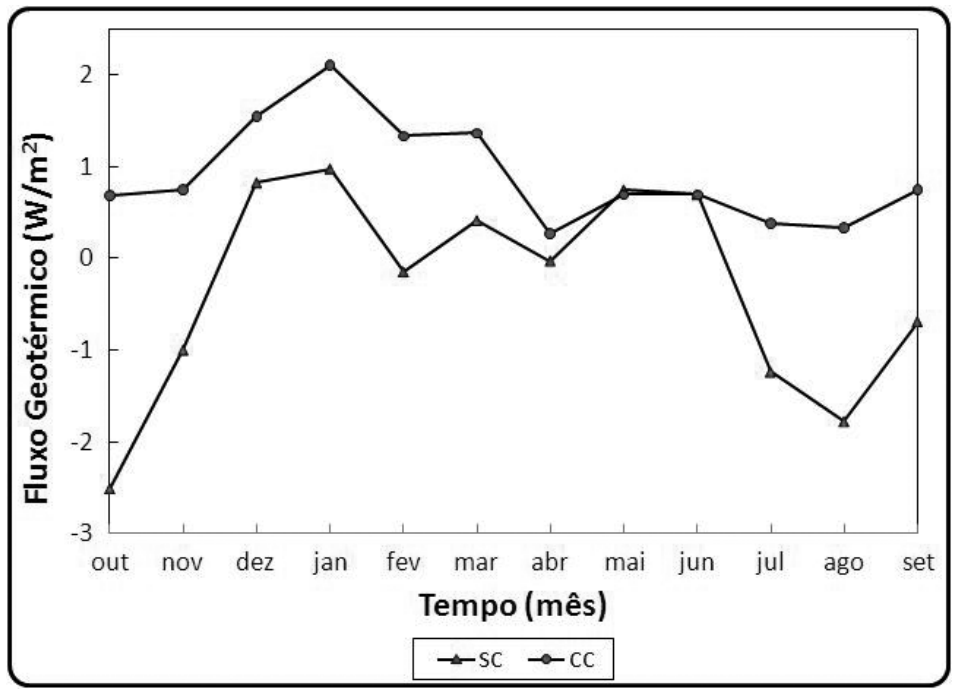

Figura 15 - Valores médios mensais do fluxo geotermal raso, a 0,5 m de profundidade, às $13 \mathrm{~h}$, para o período de outubro de 2007 a setembro de 2008, nos locais sem e com cobertura vegetal.

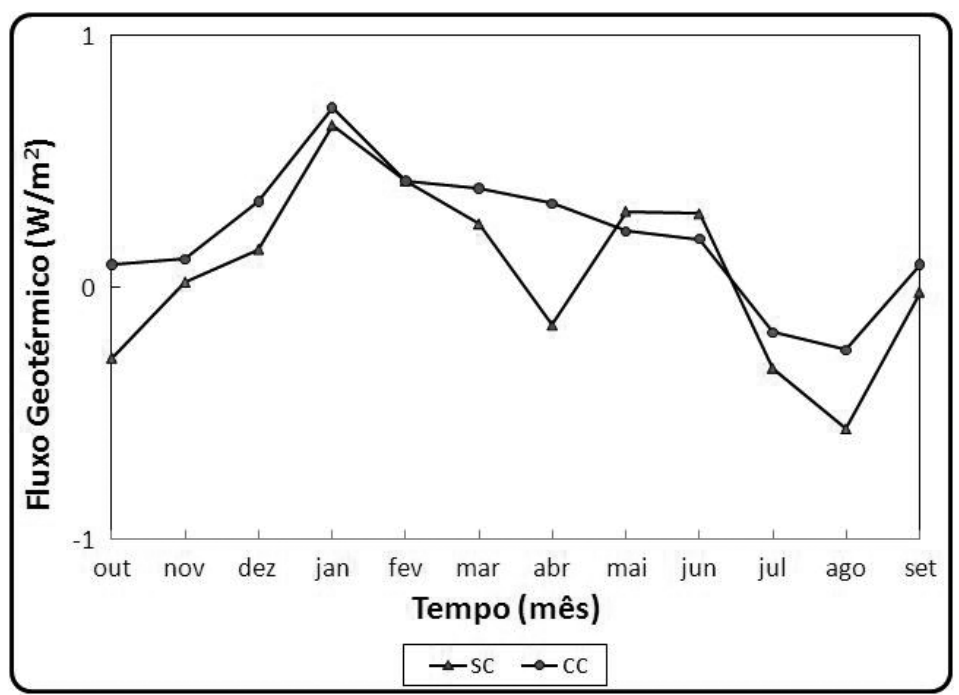

Figura 16 - Valores médios mensais do fluxo geotermal raso, a 1,0 $\mathrm{m}$ de profundidade, às $13 \mathrm{~h}$, para o período de outubro de 2007 a setembro de 2008, nos locais sem e com cobertura vegetal.

Observa-se que os valores do fluxo geotermal raso são perfeitamente mensuráveis a 1,0 m de profundidade. Mediu-se vaIores extremamente elevados em relação ao valor do fluxo médio profundo na região, portanto, não podem ser desprezíveis, e também não podem ser explicados exclusivamente como parte do fluxo de calor proveniente do interior da Terra.

\section{CONCLUSÕES}

Durante o período analisado observou-se que ocorreram variações mensuráveis nos valores diários da temperatura em todas as profundidades estudadas: $0,02 \mathrm{~m}, 0,5 \mathrm{~m}$ e 1,0 m, assim como para os valores médios mensais. As variações ocorridas a $0,5 \mathrm{~m}$ e 1,0 $\mathrm{m}$ são diretamente dependentes das mudanças térmicas ocorridas a $0,02 \mathrm{~m}$.

Observou-se que à profundidade de 1,0 m há variações significativas dos valores de temperatura diária e também dos valores médios mensais, tanto no período "seco" como no período "chuvoso". As variações dos valores médios mensais da temperatura, entre os locais cc e sc, às $13 \mathrm{~h}$, foram de $2,84^{\circ} \mathrm{C}$ no período "seco", e de $2,51^{\circ} \mathrm{C}$ no período "chuvoso". Portanto, estas variações não podem ser negligenciadas. 
Verificou-se que às $18 \mathrm{~h}$ as magnitudes da temperatura a 0,02 $\mathrm{m}$ de profundidade permanecem elevadas, em comparação aos outros horários, medidos no mesmo dia; isso é característico dos locais estudados.

A influência da cobertura vegetal na temperatura às profundidades estudadas no ciclo climático de um ano foi mensurada. No período "seco", a variação entre os valores máximos, nos locais sc e cc foi de até $9,63^{\circ} \mathrm{C}$, e a $3,97^{\circ} \mathrm{C}$ no período "chuvoso", simplesmente pelo fato de um dos locais não ter proteção da vegetação. Isto constata a mensurável influência da cobertura vegetal sobre os valores de temperatura na região estudada.

No mês de junho ocorreu a menor diferença em termos absolutos entre as médias mensais, nos locais com e sem cobertura vegetal, registrando $0,06^{\circ} \mathrm{C}$. Esse fato pode ser explicado pela ocorrência do deslocamento de massa de ar polar atlântica em direção a essa região, causando o fenômeno da "friagem", que é comum acontecer na região em estudo.

Os valores de condutividade térmica, na profundidade de $0,30 \mathrm{~cm}$, representativos dos locais estudados foram de 0,54 W/ $\mathrm{m}^{\circ} \mathrm{C}$ no período "seco" e de 1,23 W/m $\mathrm{C}$ no período "chuvoso". Observou-se que há relação direta da condutividade térmica com o conteúdo de água existente no material. Tais valores são influenciados por fatores externos e são mutáveis.

0 valor médio absoluto do fluxo geotermal raso, às $13 \mathrm{~h}$, a $0,5 \mathrm{~m}$ de profundidade, no local sem cobertura vegetal foi de $0,31 \mathrm{~W} / \mathrm{m}^{2}$, e no local com cobertura vegetal foi de $0,91 \mathrm{~W} / \mathrm{m}^{2}$, registrou-se variação de $0,60 \mathrm{~W} / \mathrm{m}^{2}$. Essa variação representa, em termos absolutos, $1,3 \times 10^{3}$ maior que 0 valor médio do fluxo profundo na região. A 1,0 m de profundidade 0 valor médio do fluxo geotermal raso, no local sem cobertura vegetal, foi de $0,06 \mathrm{~W} / \mathrm{m}^{2}$, e no local com cobertura foi de $0,21 \mathrm{~W} / \mathrm{m}^{2}$, portanto, registrou-se variação de $0,15 \mathrm{~W} / \mathrm{m}^{2}$ entre esses valores. Isso representa, em termos absolutos, 334,0 acima do valor médio do fluxo profundo terrestre na região. Observou-se que essas variações são bastante elevadas em relação ao fluxo médio profundo na região, e são mensuráveis a 1,0 m de profundidade, logo, não podem ser associadas ao fluxo de calor oriundo do interior da Terra.

\section{REFERÊNCIAS}

ARAUJO RLC. 1987. Geotermia Rasa em Belém. Tese (Doutorado em Geociências) - Centro de Geociências da Universidade Federal do Pará. $149 p$.

ARAUJO RLC. 1999. Contribuição da Geotermia Rasa aos Estudos Ambientais. EDUA, Manaus, $88 \mathrm{p}$.
ARAUJO RLC, SOUZA JRS \& MAKINO M. 1984. Análise de Perfis de Temperatura na Camada Intempérica da Área Metropolitana de Belém. In: Cong. Bras. Geol., 33: 1984, Rio de Janeiro. Anais... Rio de Janeiro: SBG, 1984. p. 2073-2088.

ARAUJO RLC, SILVA RM, CARVALHO JS \& MONTEIRO IB. 2004. Influência Ambiental sobre a Estrutura Geotermal Rasa. Revista Brasileira de Geofísica, 22(1): 33-44.

ASTIER J. 1975. Geofísica Aplicada a la Hidrogeología. Paraninfo, Madrid, $344 \mathrm{p}$.

BECK AE. 1965. Techniques of Measuring Heat Flow on Land. In: LEE WHK (Ed.). Terrestrial Heat Flow. 1965, Washington. American Geophysical Union: 1965, p. 24-57.

BOWEN R. 1966. Paleotemperature Analysis. Methods in Geochemistry and Geophysics. Elsevier, N.Y., 265 p.

CARSLAW HS \& JAEGER JC. 1959. Conduction of Heat in Solids. Oxford, $2^{\mathrm{a}}$ ed., Clarendon Press, $496 \mathrm{p}$.

CARVALHO HS. 1981. Método para Determinação de Fluxo Geotérmico com Aplicação às Bacias Sedimentares Petrolíferas do Recôncavo Baiano (Brasil) e Sumatra (Indonésia). Tese (Doutorado). Universidade Federal da Bahia. 92 p.

CARVALHO AM. 1986. Caracterização física, química e mineralógica dos solos do município de Humaitá-AM. Tese de Livre Docência. Universidade do Estado de São Paulo, campus de Botucatu. 166 p.

CARVALHO HS, LOBO PFS, CAMPOS JNP \& ZEMBRUSCKI SG. 1986. Heat Flow and Hydrodynamic Study in the Medium Amazon Basin. In: International Meeting on Geothermics and Geothermal Energy, São Paulo, 1986. p. 107.

CHU PS, YU Z-P \& HASTENRATH S. 1999. Detecting Climate Change concurrent with Deforestation in the Amazon Basin: which way has it gone? Bull. Amer. Meteorol. Soc., 75: 579-583.

DICKINSON RE \& KENNEDY P. 1999. Impacts on regional climate of Amazon deforestation. Geophys. Res. Lett., 19(19): 1947-1950.

EMBRAPA - Empresa Brasileira de Pesquisa Agropecuária. 1997. Secretaria de Assuntos Estratégicos (SAE). Estudo de viabilidade agrícola de cerrados do Amazonas. Brasília, DF. BNDES. Relatório técnico. 91 p.

HIODO FY, ARAUJO RLC, SILVA JE \& BLANE K. 2007. Construção de um sistema automático para monitoração geotermal rasa. In: Cong. Intern. Geofis., 10: 2007, Rio de Janeiro. Anais... Rio de Janeiro: SBGf, 2007. CD-ROM. 6 p.

KALNAY E \& CAI M. 2003. Impact of Urbanization and Land-Use Change on Climate. Nature, 423: 528-531.

LEAN J, BUNTON CB, NOBRE CA \& ROWNTREE PR. 1996. The simulated impact of Amazonian deforestation on climate using measured 
ABRACOS vegetation characteristics. In: GASH JHC, NOBRE CA, ROBERTS JM \& VICTORIA RL. (Ed.). Amazonian Deforestation and Climate. John Wiley \& Sons, England, p. 549-576.

MARTINS GC, FERREIRA MM, CURI N, VITORINO ACT \& SILVA MLN. 2006. Campos Nativos e Matas Adjacentes da Região de Humaitá (AM): Atributos Diferenciais dos Solos. Ciência e Agrotecnologia, 30: 221-227.

OLIVEIRA FNM, ARAUJO RLC, CARVALHO JS \& SILVA CL. 2006. Inferência de Mudanças Climáticas na Região de Manaus (AM) usando Dados Geotermais e Meteorológicos. Revista Brasileira de Geofísica, 24(2): 169-187.

OLIVEIRA FNM, ARAUJO RLC, CARVALHO JS \& COSTA SS. 2008. Determinação da Variação no Microclima de Manaus-AM, por Atividades Antropogênicas e Modulações Climáticas Naturais. Acta Amazonica, 38(4): 687-700.

PALHA WSM, ARAUJO RLC \& CARVALHO JS. 1998. Fluxo Geotermal Raso Aplicado aos Estudos Ambientais. In: Cong. Bras. Geol., 40: 1998, Belo Horizonte. Anais... Belo Horizonte: SBG, 1998. p. 138-141.

ROY RF, BLACKWELL DD \& DECKER ER. 1971. Continental heat flow.
In: ROBERTSON EC (Ed.). The Nature of the Solid Earth. N.Y., McGrawHill, p. 506-543.

SERRA PN. 2002. Determinação da Profundidade de Influência da Perturbação Térmica Sazonal Gerada pelo Aquecimento Solar na Região Metropolitana de Manaus. Dissertação (Mestrado) - Universidade Federal do Amazonas. $80 \mathrm{p}$.

SERRA PN, ARAUJO RLC, CARVALHO JS \& PALHA WSM. 1997. Caracterização Geotérmica no Campus da Universidade Federal do Amazonas. In: Cong. Intern. Geofís., 5: 1997, São Paulo. Anais... São Paulo: SBGf, 1997. p. 946-949.

SMITH PJ. 1973. Topics in Geophysics. The Open University Press. N. Y., $303 p$.

SOUZA JRS, MAKINO M, ARAUJO RLC, COHEN JCP \& PINHEIRO FMA. 2006. Thermal Properties and Heat Fluxes in Soils under Forest and Pasture in Marabá, PA, Brazil. Rev. Bras. Meteor., 21: 89-103.

VON HERZEN R \& MAXWELL AE. 1959. The measurement of thermal conductivity of deep-sea sediments by a needle probe method. Journal of Geophysical Research, 64: 1557-1563.

\section{NOTAS SOBRE OS AUTORES}

Elizabeth Tavares Pimentel. Graduada em Física pela Universidade Federal do Amazonas, em 1998. Mestre em Geociências pela Universidade Federal do Amazonas, em 2009. Atualmente está cursando Doutorado em Geofísica no Observatório Nacional/RJ. É Professora Assistente da Universidade Federal do Amazonas/IEAA, onde exerce a função de docente e pesquisadora desde 0 ano de 2006, também exerceu a função administrativa de Coordenadora do Curso Ciências: Matemática e Física. Atua na área de Física Geral e Aplicada, como também, em Geofísica Aplicada, com ênfase em Geotermia.

Rutenio Luiz Castro de Araujo. Graduado em Física pela Universidade Federal do Rio de Janeiro, em 1973. Mestre em Geofísica pela Universidade de São Paulo, em 1978 e Doutor em Geofísica pela Universidade Federal do Pará, em 1987. Atualmente é Professor Titular da Universidade Federal do Amazonas, onde exerce a função de docente e pesquisador desde 0 ano de 1980, tendo exercido várias funções administrativas, como Chefe de Departamento Acadêmico e Pró-Reitor de Pesquisa e Pós-Graduação. Atua na área de Geofísica Aplicada, principalmente em Geofísica Ambiental, com ênfase na Amazônia.

lerecê Barbosa Monteiro. Licenciada em Pedagogia pela Universidade Federal do Pará (UFPA). Bacharel em Comunicação Social (Jornalismo e Relações Públicas) pela Universidade Federal do Amazonas (UFAM). Mestre em Educação (UFAM) e Doutora em Educação pela Universidade Federal do Rio Grande do Norte (UFRN). Exerceu vários cargos administrativos, tais como: Coordenadora do Curso de Comunicação Social (UFAM), Chefe de Departamento (UFAM), Assessora de Comunicação Social (UFAM) e Pró-Reitora de Ensino de Graduação (UFAM). Atualmente é Professora da Universidade do Estado do Amazonas (UEA) e do Centro Universitário do Norte. Faz parte dos Programas de Mestrado em Engenharia de Produção (UFAM) e Ensino de Ciências (UEA). Tem como áreas de atuação profissional a educação, a comunicação, estratégia e organização e estudos ambientais.

Roberto Matias da Silva. Em 1983, bacharelou-se em Geologia pela Universidade Federal do Amazonas. Em 2003, concluiu Mestrado em Geologia Ambiental, Linha de Pesquisa: Geofísica e Geotermia Ambiental, pela mesma instituição, atuou como Geólogo, na Mineração Oriente Novo, em Rondônia, exploração de cassiterita, onde foi Gerente de Mina. Desde 1991 atua como pesquisador da Fundação de Tecnologia do Estado do Acre (FUNTAC), onde foi Diretor Técnico e de Produção e Diretor Presidente. Atualmente exerce a função de Pesquisador II. Em 2004 assumiu o cargo de Professor da Uninorte/AC. 